\title{
PERANAN PENYULUHAN KESEHATAN GIGI DAN MULUT TERHADAP PENINGKATAN KEBERSIHAN GIGI DAN MULUT SISWA-SISWI KELAS VII-1 SMP N 31 MEDAN KECAMATAN MEDAN TUNTUNGAN TAHUN 2014
}

\author{
Nelly Katharina Manurung \\ Jurusan Keperawatan Gigi
}

\begin{abstract}
Abstrak
Anak usia sekolah merupakan kelompok yang rentan terhadap penyakit gigi dan mulut, seperti masalah gigi berlubang, bau mulut, karang gigi dan pola makan yang dapat mempengaruhi kesehatan gigi dan mulut. Oleh karena itu anak sekolah perlu mendapat perhatian khusus dalam hal peningkatan derajat kesehatan gigi dan mulut yang optimal. Upaya yang dapat dilakukan untuk meningkatkan derajat kesehatan gigi salah satunya adalah dengan memberikan pendidikan kesehatan gigi melalui penyuluhan. Penelitian ini bersifat diskriptif dengan menggunakan pretest-posttest design dengan memberikan perlakuan berupa penyuluhan kesehatan gigi dan mulut dengan metode ceramah dan demonstrasi yang bertujuan untuk mengetahui peranan penyuluhan kesehatan gigi terhadap peningkatan kebersihan gigi dan mulut siswa. Penelitian ini merupakan penelitian populasi yang dilakukan pada siswa-siswi kelas VII-1 SMP N 31 Medan Kecamatan Medan Tuntungan dengan jumlah responden 40 orang. Penelitian dilakukan dengan cara pemeriksaan langsung dan diperoleh hasil bahwa penyuluhan sangat berperan penting dalam meningkatkan kebersihan gigi dan mulut. Hal ini dapat dilihat dari adanya perbedaan yang nyata pada rata-rata $\mathrm{OHI}-\mathrm{S}$ siswa sebelum dan sesudah penyuluhan. Oral Hygiene Index Simplified (OHI-S) siswa-siswi sebelum penyuluhan 3.37 dengan kriteria buruk dan setelah penyuluhan menjadi 2.05 dengan kriteria sedang. Persentase OHI-S sebelum penyuluhan dengan kriteria buruk yaitu $60 \%$ sesudah penyuluhan menjadi $7,5 \%$, dengan kriteria sedang yaitu 30\% menjadi $75 \%$ dan tidak dijumpai (0\%) siswa dengan angka OHI-S dalam kriteria baik sebelum penyuluhan, namun setelah penyuluhan meningkat menjadi 17,5\%. Dari hasil penelitian tersebut menunjukkan bahwa penyuluhan kesehatan gigi dan mulut sangat berperan penting dalam meningkatkan kebersihan gigi dan mulut.
\end{abstract}

Kata kunci : Penyuluhan, Kebersihan Gigi dan Mulut

\section{PENDAHULUAN}

Masalah gigi dan mulut yang banyak diderita masyarakat pada umumnya meliputi gigi berlubang (karies), radang gusi, karang gigi (Calculus) yang seharusnya dapat dicegah sejak dini. Menurut Survei Organisasi Kesehatan Dunia (WHO) tahun 2003, dalam satu bulan terdapat $62 \%$ masyarakat pernah sakit gigi dan hasil Survei Habit and Attitude tahun 2004 di Indonesia dinyatakan bahwa tingginya angka penyakit gigi dan mulut disebabkan kurangnya perhatian masyarakat dalam upaya membersihkan gigi dan mulut.

Penyuluhan kesehatan gigi dan mulut adalah upaya-upaya yang dilakukan untuk merubah perilaku seseorang, sekelompok orang atau masyarakat sehingga mempunyai kemampuan dan kebiasaan untuk berperilaku hidup sehat di bidang kesehatan gigi dan mulut (Depkes, 1995).

Karies atau gigi berlubang serta masalah gusi adalah penyakit gigi dan mulut yang paling banyak ditemui pada anak. Sebanyak 89\% anak di Indonesia dibawah usia 12 tahun menderita penyakit gigi dan mulut. Kondisi ini akan berpengaruh pada derajat kesehatan mereka. Maka untuk menurunkan jumlah tersebut selain tindakan pengobatan bagi anak usia sekolah perlu juga dilakukan tindakan promotif (penyuluhan) bagi sekolah dasar untuk menumbuhkan kesadaran dalam membersihkan gigi dan mulut, karena masa ini merupakan masa tumbuh dan berkembang (Astoeti, 2007).

Berdasarkan uraian di atas, maka penulis tertarik melakukan penelitian tentang bagaimana " Peranan Penyuluhan Kesehatan Gigi dan Mulut Terhadap Peningkatan Kebersihan Gigi dan Mulut pada Siswa-siswi Kelas VII-1 SMP N 31 Medan Kecamatan Medan Tuntungan Tahun 2014."

\section{Tujuan Penelitian}

Untuk mengetahui bagaimana "Peranan Penyuluhan Kesehatan Gigi dan Mulut Terhadap Peningkatan Kebersihan Gigi dan Mulut pada Siswasiswi Kelas VII-1 SMP N 31 Medan Kecamatan Medan Tuntungan Tahun 2014." 


\section{Manfaat Penelitian}

1. Menambah pengetahuan, pengalaman dan wawasan bagi penulis tentang bagaimana motivasi anak dalam meningkatkan kebersihan gigi dan mulut.

2. Memberikan masukan bagi penyelenggara pelayanan kesehatan dalam meningkatkan pelayanan kesehatan gigi dan mulut.

3. Sebagai masukan bagi peneliti lain dalam melakukan penelitian selanjutnya.

\section{METODE PENELITIAN}

\section{Jenis dan Desain Penelitian}

Penelitian ini adalah penelitian deskriptif dengan menggunakan pretest-posttest design. Pada siswa-siswi kelas VII-1 SMP N 31 sebelum dilakukan penyuluhan terlebih dahulu dilakukan pemeriksaan terhadap kebersihan gigi dan mulut siswa. Selanjutnya setelah dilakukan penyuluhan, peneliti melakukan pemeriksaan ulang terhadap kebersihan gigi dan mulut untuk mengetahui akibat dari perlakuan (penyuluhan). Hasilnya dilihat dengan cara membandingkan angka kebersihan gigi dan mulut anak sebelum dan sesudah penyuluhan dilakukan.

\section{Lokasi dan Waktu Penelitian}

Lokasi penelitian ini adalah SMP Negeri 31 Kecamatan Medan Tuntungan. Penelitian ini dilakukan selama 5 bulan dari bulan Maret sampai Juli 2014 terhadap siswa-siswi kelas VII-1 SMP N 31 Medan Kecamatan Medan Tuntungan. Sekolah ini dipilih karena pada sekolah tersebut belum pernah dilakukan penyuluhan kesehatan gigi dan mulut khususnya cara menyikat gigi yang baik dan benar.

\section{Populasi dan Sampel Penelitian}

Mengacu kepada pendapat Arikunto (2002). Jika sampel kurang dari 100, lebih baik diambil semua sehingga penelitiannya merupakan penelitian populasi. Maka sampel yang digunakan dalam penelitian ini adalah populasi total dari siswa-siswi Kelas VII-1 SMP N 31 Medan Kecamatan Medan Tuntungan 2014 yang berjumlah 40 orang.

\section{Jenis dan Cara Pengumpulan Data}

Dalam penelitian ini data yang digunakan adalah data primer dan data sekunder. Data primer dalam penelitian ini berupa data tingkat kebersihan gigi dan mulut siswa siswi yang diperoleh melalui pemeriksaan langsung ke rongga mulut siswa siswi. Data sekunder diperoleh dari pihak sekolah yang berupa data tentang nama, alamat dan jumlah siswa siswi.

Hal pertama yang dilakukan oleh peneliti adalah melakukan pemeriksaan langsung terhadap sampel untuk mendapatkan data awal mengenai kebersihan gigi dan mulut dari sampel yang akan diteliti, kemudian melakukan penyuluhan dengan metode ceramah dan demonstrasi. Setelah penyuluhan dilakukan satu minggu kemudian peneliti melakukan kembali pemeriksaan langsung ke mulut pasien yang menjadi sampel untuk mendapatkan data akhir mengenai kebersihan gigi dan mulut. Sehingga dari data awal dan data akhir yang diperoleh, terlihat adanya perubahan tingkat kebersihan gigi dan mulut siswa siswi.

Pengumpulan data dilakukan oleh tim yang terdiri dari 3 orang.

Pengumpulan data dilakukan dengan cara sebagai berikut :

1. Orang pertama memanggil nama-nama yang menjadi sampel dan mendudukkannya di kursi yang telah disediakan.

2. Orang kedua melakukan pemeriksaan gigi pada sampel dengan tujuan untuk mengetahui tingkat kebersihan gigi dan mulutnya (OHI-S) dengan menggunakan alat oral diagnostic dan peralatan lain yang dibutuhkan.

3. Untuk mengetahui tingkat kebersihan gigi dan mulut maka cara yang digunakan adalah cara Green dan Vermilion yaitu hasil dari penjumlahan debris Index dan Calculus Index. Cara pemeriksaannya adalah sebagai berikut :

Untuk rahang atas yang diperiksa adalah :

- $\quad$ Gigi M1 kanan atas pada permukaan bukal

- $\quad$ Gigi I1 kanan atas pada permukaan labial

- $\quad$ Gigi M1 kiri atas pada permukaan bukal

Untuk rahang bawah yang diperiksa adalah :

- $\quad$ Gigi M1 bawah pada permukaan lingual

- $\quad$ Gigi I1 kiri bawah pada permukaan labial

- $\quad$ Gigi M1 kanan bawah pada permukaan lingual

4. Kemudian hasil pemeriksaan dicatat oleh orang ketiga pada formulir pemeriksaan yang telah disiapkan.

5. Setelah itu, formulir pemeriksaan dikumpulkan dan dihitung serta diperiksa kelengkapannya agar terhindar dari kekurangan data dan mempermudah dalam pengolahan data. Jika data tersebut belum lengkap, maka harus dilengkapi terlebih dahulu.

6. Menghitung debris Index dan Calculus Index. Kemudian debris Index dan Calculus Index dijumlahkan sehingga hasil penjumlahan tersebut merupakan angka untuk menentukan tingkat kebersihan gigi dan mulut (OHI-S).

7. Menghitung jumlah sampel yang memiliki OHI-S baik, sedang dan buruk.

8. Selanjutnya dilakukan penghitungan persentase kebersihan gigi dan mulut siswa yang menjadi sampel menurut kriteria baik, sedang dan buruk. Kemudian data-data tersebut dimasukkan kedalam tabel distribusi frekuensi.

\section{Pengolahan dan Analisis Data}

Data yang telah terkumpul diolah secara manual dengan langkah-langkah sebagai berikut:

- Data yang diperoleh dimasukkan ke dalam tabel distribusi frekuensi untuk mengetahui perbandingan tingkat kebersihan gigi dan mulut siswa sebelum dilakukan penyuluhan dan sesudah penyuluhan. 
- Data yang telah terkumpul dianalisa dengan langkah menghitung rata-rata OHI-S sebelum dan sesudah penyuluhan dengan menggunakan rumus sebagai berikut :

1. Untuk debris Index rata-rata:

Debris Index Rata-Rata

$=\frac{\text { Jumlah Debris Index Total }}{\text { Jumlah Anak yang Diperiksa }}$

2. Untuk Calculus Index rata-rata:

Calculus Index Rata-Rata

$=\frac{\text { Jumlah Calculus Index Total }}{\text { Jumlah Anak yang Diperiksa }}$

3. Untuk OHI-S rata-rata:

OHI-S Rata-Rata

$$
=\frac{\text { Jumlah OHI }-\mathrm{S} \text { Total }}{\text { Jumlah Anak yang Diperiksa }}
$$

Sehingga untuk mengetahui hasil akhir atau peningkatan kebersihan gigi dan mulut $(\mathrm{P})$ yaitu:

$\mathrm{P}=\mathrm{OHI}-\mathrm{S}$ rata-rata awal $-\mathrm{OHI}-\mathrm{S}$ rata-rata akhir

$\mathrm{P}=$ Peningkatan kebersihan gigi dan mulut

\section{HASIL PENELITIAN DAN PEMBAHASAN}

\section{Hasil Penelitian}

Penelitian yang dilakukan pada 40 orang siswasiswa kelas VII-1 SMP N 31 Medan Kecamatan Medan Tuntungan Tahun 2014 menunjukkan hasil sebagai berikut:

Tabel A.1

Distribusi Frekuensi Debris Index (DI) Rata-rata Sebelum dan Sesudah Penyuluhan pada Siswa-siswi Kelas VII-1 SMP N 31 Medan Kecamatan Medan Tuntungan Tahun 2014

\begin{tabular}{lcccccccc} 
Kriteria & \multicolumn{3}{l}{ Sebelum Penyuluhan } & \multicolumn{3}{l}{ Sesudah penyuluhan } \\
\cline { 2 - 9 } & $\mathbf{n}$ & $\begin{array}{l}\text { Jumlah Rata-rata DI } \\
\text { DI }\end{array}$ & & & N & Jumlah DIRata-ratz & \% \\
DI & \\
\hline 3aik & 0 & 0 & 0 & 0 & 8 & 2,48 & 0,31 & 20 \\
\hline iedang & 14 & 23,95 & 1,71 & 35 & 31 & 33,8 & 1,09 & 77,5 \\
\hline 3uruk & 26 & 58,73 & 2,25 & 65 & 1 & 2,50 & 2,50 & 2,5 \\
\hline Total & $\mathbf{4 0}$ & $\mathbf{8 2 , 4 8}$ & $\mathbf{2 , 0 6}$ & $\mathbf{1 0 0}$ & $\mathbf{4 0}$ & $\mathbf{3 8 , 7 8}$ & $\mathbf{0 , 9 6}$ & $\mathbf{1 0 0}$ \\
\hline
\end{tabular}

Dari tabel diatas dapat dilihat bahwa jumlah siswa dengan Debris Index (DI) kriteria buruk sebelum penyuluhan berjumlah 26 siswa (65\%), setelah penyuluhan berkurang menjadi menjadi 1 siswa $(2,5 \%)$. Siswa dengan Debris Index kriteria sedang sebelum penyuluhan berjumlah 14 orang $(35 \%)$ dan sesudah penyuluhan menjadi 31 siswa (77,5\%). Sebelum penyuluhan tidak ada siswa yang memiliki Debris Index dengan kriteria baik, namum setelah penyuluhan meningkat mejadi 8 orang (20\%). Debris Index rata-rata sebelum penyuluhan adalah 2,06 dan sesudah penyuluhan menurun menjadi 0,96.
Tabel A.2

Distribusi Frekuensi Calculus Index (CI) Rata-rata Sebelum dan Sesudah Penyuluhan pada Siswa-siswa Kelas VII-1 SMP N 31 Medan Kecamatan Medan Tuntungan Tahun 2014

\begin{tabular}{lcccccccc} 
& \multicolumn{3}{c}{ Sebelum penyuluhan } & \multicolumn{3}{c}{ Sesudah Penyuluhan } \\
Kriteria & \multicolumn{3}{c}{ umlah CRata-rata } & $\mathbf{\%}$ & $\mathbf{N}$ & Jumlah Rata-rata & \% \\
& & $\mathbf{n}$ & DI & & & CI & DI & \\
\hline 3aik & 3 & 1,50 & 0,50 & 7,5 & 8 & 1,50 & 0,18 & 20 \\
\hline iedang & 30 & 35,4 & 1,18 & 75 & 27 & 31,92 & 1,18 & 67,5 \\
\hline 3uruk & 7 & 14,33 & 2,04 & 17,5 & 5 & 10 & 2,00 & 12,5 \\
\hline Total & $\mathbf{4 0}$ & $\mathbf{5 1 , 2}$ & $\mathbf{1 , 2 8}$ & $\mathbf{1 0 0}$ & $\mathbf{4 0}$ & $\mathbf{4 3 , 4 2}$ & $\mathbf{1 , 0 8}$ & $\mathbf{1 0 0}$ \\
\hline
\end{tabular}

Dari tabel diatas dapat dilihat bahwa jumlah siswa dengan Calculus Index (CI) kriteria buruk sebelum penyuluhan berjumlah 7 siswa $(17,5 \%)$, setelah penyuluhan berkurang menjadi menjadi 5 siswa (12,5\%). Siswa dengan Calculus Index kriteria sedang sebelum penyuluhan berjumlah 30 orang $(75 \%)$ dan sesudah penyuluhan menjadi 27 siswa $(67,5 \%)$. Sebelum penyuluhan terdapat 3 siswa $(7,5 \%)$ yang memiliki Calculus Index dengan kriteria baik, namum setelah penyuluhan meningkat mejadi 8 orang $(20 \%)$. Calculus Index rata-rata sebelum penyuluhan adalah 1,28 dan sesudah penyuluhan menurun menjadi 1,08.

Tabel A.3

Distribusi Frekuensi OHI-S Rata-rata Sebelum dan Sesudah Penyuluhan pada Siswa-siswi Kelas VII-1 SMP N 31 Medan Kecamatan Medan Tuntungan Tahun 2014

\begin{tabular}{ccccccccc} 
Kriteria & \multicolumn{3}{c}{ Sebelum Penyuluhan } & \multicolumn{4}{c}{ Sesudah Penyuluhan } \\
\cline { 2 - 9 } & $\mathbf{N}$ & $\begin{array}{c}\text { Jumlah } \\
\text { OHI-S }\end{array}$ & $\begin{array}{c}\text { Rata-rata } \\
\text { OHI-S }\end{array}$ & $\%$ & N & $\begin{array}{c}\text { Jumlah Raa-rata } \\
\text { OHI-S }\end{array}$ & OHIS & $\%$ \\
\hline Baik & 0 & 0 & 0 & 0 & 7 & 5,8 & 0,82 & 17,5 \\
\hline Sedang & 16 & 41,38 & 2,58 & 40 & 30 & 66,08 & 2,20 & 75 \\
\hline Buruk & 24 & 93,53 & 3,89 & 60 & 3 & 10,29 & 3,43 & 7,5 \\
\hline Total & $\mathbf{4 0}$ & $\mathbf{1 3 4 , 9 1}$ & $\mathbf{3 , 3 7}$ & $\mathbf{1 0 0}$ & $\mathbf{4 0}$ & $\mathbf{8 2 , 1 7}$ & $\mathbf{2 , 0 5}$ & $\mathbf{1 0 0}$ \\
\hline
\end{tabular}

Dari tabel di atas dapat dilihat bahwa OHI-S siswa sebelum penyuluhan pada 24 siswa $(60 \%)$ dengan kriteria buruk sesudah penyuluhan menjadi 3 siswa (7,5\%), 16 siswa (40\%) dengan kriteria sedang sesudah penyuluhan menjadi $30(75 \%)$. Sebelum penyuluhan dilakukan tidak ada siswa yang tingkat kebersihan mulutnya dalam kriteria baik, namun sesudah penyuluhan meningkat menjadi 7 siswa $(17,5 \%)$. Rata-rata OHI-S sebelum penyuluhan yaitu 3.37 dengan kriteria buruk dan sesudah penyuluhan menjadi 2.05 dengan kriteria sedang dan terjadi penurunan angka OHI-S sebesar 1,32.

\section{Pembahasan}

Dari hasil pemeriksaan langsung yang dilakukan terhadap kebersihan gigi dan mulut siswa-siswi sebelum dan sesudah penyuluhan terlihat adanya peningkatan.

Debris Index rata-rata sebelum penyuluhan yaitu sebesar 2,06 dengan kriteria buruk, sesudah penyuluhan menjadi 0,96 dengan kriteria sedang. Menurut Ali Thanthawi (2010) kesehatan mulut berkaitan dengan kebersihan gigi, banyaknya kuman dan bakteri penyakit yang berada di dalam sisa makanan dan menempel di sela- 
sela gigi. Sisa makanan akan membusuk dan berubah menjadi sarang kuman sehingga bila mengabaikan kebersihan gigi dan mulut pada akhirnya akan membuat gigi mudah berlubang dan keropos.

Calculus Index rata-rata sebelum penyuluhan yaitu sebesar 1,28 dengan kriteria sedang dan sesudah penyuluhan menjadi 1,08. Ini disebabkan karena sisa makanan dan bakteri mudah menempel dan berkembang biak pada permukaan yang kasar karena adanya calculus, sehingga apabila calculus tidak dibersihkan akan menimbulkan penyakit gigi dan mulut. Menurut Nio (1989), karang gigi juga tempat yang baik untuk pertumbuhan plak. Karang gigi yang tidak dibersihkan akan mengakibatkan gingivitis, bau mulut, karies gigi dan gigi goyang. Wahit,dkk, 2006, menyatakan pendidikan kesehatan adalah proses perubahan perilaku yang dinamis dan perubahan tersebut bukan sekedar proses transfer materi/teori dari seseorang ke orang lain dan bukan pula seperangkat prosedur, akan tetapi perubahan tersebut terjadi karena adanya kesadaran dari dalam diri individu, kelompok atau masyarakat.

OHI-S rata-rata sebelum penyuluhan sebesar 3,37 dengan kriteria buruk, sesudah penyuluhan menjadi 2,05 dengan kriteria sedang. Hal ini disebabkan karena penyuluhan yang diberikan hanya pada saat penelitian berlangsung. Apabila penyuluhan diberikan secara berkesinambungan dan pihak sekolah juga mendukung tindakan pemeliharaan kesehatan gigi dan mulut siswa, diharapkan rata-rata $\mathrm{OHI}-\mathrm{S}$ dengan kriteria baik akan lebih meningkat. Kurangnya perhatian siswa untuk menjaga kesehatan gigi dan mulutnya dapat menyebabkan tingkat kebersihan gigi dan mulut semakin buruk dan dapat merusak gigi. Menurut Lena (2011), pemeliharaan kesehatan gigi dan mulut dengan cara menyikat gigi berperan sangat besar, karena dapat mencegah penumpukan plak dan menimbulkan kerusakan jaringan penyangga gigi.

Herijulianti, E, 2001, menyatakan bahwa tujuan penyuluhan dalam jangka pendek adalah tercapainya perubahan pengetahuan masyarakat. Tujuan jangka menengah adalah untuk meningkatkan pengertian sikap dan keterampilan yang akan mengubah perilaku seseorang kearah perilaku sehat. Tujuan jangka panjang adalah agar masyarakat dapat menjalankan perilaku sehat dalam kehidupannya sehari-hari.

\section{SIMPULAN DAN SARAN}

\section{Simpulan}

Berdasarkan hasil penelitian mengenai Peranan Penyuluhan Kesehatan Gigi dan Mulut Terhadap Peningkatan Kebersihan Gigi dan Mulut Siswa-siswi Kelas VII-1 SMP N 31 Medan Kecamatan Medan Tuntungan Tahun 2014, dapat disimpulkan bahwa penyuluhan sangat berperan penting dalam meningkatkan kebersihan gigi dan mulut siswa kelas VII-1. Hal tersebut dapat diuraikan sebagai berikut:

1. OHI-S menjadi lebih baik yang dapat dilihat dari tidak adanya siswa yang memiliki tingkat kebersihan gigi dan mulut yang baik sebelum penyuluhan, namun setelah penyuluhan siswa dengan tingkat kebersihan mulut yang baik meningkat menjadi 7 orang $(17,5 \%)$.

2. Rata-rata OHI-S menjadi lebih baik dilihat dari angka OHI-S rata-rata sebelum penyuluhan 3.37 dan sesudah penyuluhan menjadi 2.05 .

\section{Saran}

Berdasarkan hasil penelitian yang telah dilakukan diharapkan kepada:

1. Pihak SMP N 31 Medan Kecamatan Medan Tuntungan bekerja sama dengan puskesmas setempat untuk dapat memberikan penyuluhan kesehatan gigi dan mulut secara berkala sehingga siswa mampu memelihara kebersihan gigi dan mulut secara optimal.

2. Siswa-siswi SMP N 31 Medan Kecamatan Medan Tuntungan untuk meningkatkan kesehatan gigi dan mulut yaitu dengan cara menyikat gigi minimal 2 kali sehari yaitu pagi sesudah makan dan malam sebelum tidur dan melakukan pemeriksaan kesehatan gigi secara berkala minimal 6 bulan sekali.

\section{DAFTAR PUSTAKA}

Arikunto, S., 2002. Prosedur Penelitian. Rineka Cipta, Jakarta.

Astoeti, 2006. Pendidikan Kesehatan Gigi di Sekolah. EGC. Jakarta.

Boediharto, 1998. Pendidikan Kesehatan Gigi. FKG, UI. Jakarta.

_ 1985. Pemeliharaan Kesehatan Bagi Keluarga. Airlangga University Press. Jakarta.

Effendy, Nasrul, 1998. Dasar-Dasar Keperawatan Kesehatan Masyarakat. EGC. Jakarta.

Gent, B. Van, 2000. Andragologie En Voorlichting. Proefschrift, Boom. Meppel.

Herijulianti, S., Tati Svasti Indriani, Sri Artini. Pendidikan Kesehatan Gigi. EGC, Jakarta. 2001

Green, Lawrence, 1980. Health Education Planning, A Diagnostic Approach. The John Hopkins Univercity, Mayfielt Publishing Co.

PDK Direktorat PLS, Pemuda dan OR. Balai Pengembangan Kegiatan, Lembang, Metode Ceramah. Bandung. 1988.

Nasution, S. Berbagi Pendekatan Dalam Proses Belajar Mengajar, Bandung. Bina Aksara.

Notoatmodjo, Soekidjo. Promosi Kesehatan dan Ilmu Perilaku, Rineka Cipta, Jakarta. 2007.

Putri, H. M.,E. Herijulianti dan N Nurjanah, 2010. Ilmu Pencegahan Penyakit Jaringan Keras dan Jaringan Pendukung Gigi, EGC. Jakarta.

Ramadhan, A.G., 2010, Serba-Serbi Kesehatan Gigi dan Mulut, Bukune. Jakarta.

Rouwenhorst, W. Leren Gezond Te Ujn, 2002, Proefchrift, Walters Nuordhoof, B. V, Bronifigen.

Setiana, L., 2005. Teknik Penyusunan Pemberdayaan Masyarakat.

Wahit, dkk, 2007. Promosi Kesehatan, Graha Ilmu. Yogyakarta. 